\title{
ОТНОШЕНИЕ ОБЩЕСТВА К ПЕРИНАТАЛЬНЫМ ПОТЕРЯМ
}

\section{STUDY OF THE FACTORS ASSOCIATED WITH THE ATTITUDE OF SOCIETY TOWARDS PERINATAL LOSSES}

\section{E. Markman}

Summary: In modern society, the discussion of perinatal losses and the issues associated with them belongs to closed and taboo topics. Discussion of the topic of death is limited both in the family and in the system of providing psychological assistance to the population. Spontaneous abortion during pregnancy and stillbirth are considered less significant events than the death of a live birth. The success of psychological support during the experience of perinatal loss affects the improvement of the mental health of women who have experienced such losses, and, therefore, contributes to an improvement in the quality of life and the solution of demographic problems facing society.

The author examines the differences in attitudes towards perinatal loss between men and women. An overview of domestic and foreign modern studies is presented, reflecting the severity of this problem. An analysis of scientific works and studies in the field of perinatal losses showed that empirical data on the attitude of men and women to perinatal losses are practically absent. The scientific novelty of the research lies in the study of age and sex characteristics of attitudes towards perinatal losses; as well as the peculiarities of society's attitude to various types of perinatal losses. The methodological basis of the study was the theoretical provisions on loss as a psychological trauma by F. Ruppert, D. Kalshed, L.V. Trubitsyna, N.V. Tarabrina, J. Bowlby, S. Rubin.

The study sample consisted of women and men aged $19-40$ years $(\mathrm{M}=36)$

The study used the author's questionnaire aimed at studying the attitude of society towards perinatal loss. The results of an empirical study of attitudes towards perinatal losses and types of psychological assistance are presented.

The prospect of further research is aimed at exploring strategies for overcoming perinatal loss chosen by women who have experienced such a loss, and creating a program to provide psychological support after the loss.

Keywords: perinatal loss, grief, miscarriage, miscarriage, psychological trauma.

\author{
Маркман Елена Валерьевна \\ Аспирант, Русская Христианская \\ Гуманитарная академия; \\ преподаватель, Институт Практической психологии \\ lev195197@gmail.com
}

Аннотация: В современном обществе обсуждение перинатальных потерь и вопросов, связанных с ними, относится к закрытым и табуированным темам. 0бсуждение темы смерти ограничено как в семье, так и в системе оказания психологической помощи населению. Самопроизвольный аборт во время беременности и мертворождение, считается менее значимым событием, чем смерть живорожденного ребенка. Успешность психологического сопровождения при переживании перинатальной потери влияет на улучшение психического здоровья женщин, переживших такие потери, и, следовательно, способствует улучшению качества жизни и решению демографических задач, стоящих перед обществом.

Автор рассматривает различия в отношении к перинатальным утратам между мужчинами и женщинами. Представлен обзор отечественных и зарубежных современных исследований, отражающих степень остроты указанной проблемы. Анализ научных работ и исследований в области перинатальных потерь показал, что эмпирические данные об отношении мужчин и женщин к перинатальным утратам практически отсутствуют. Научная новизна исследования заключается в изучении возрастных и половых особенностей отношения к перинатальным утратам; а также особенности отношения общества к различным видам перинатальных утрат.

Методологической основой исследования являлись теоретические положения об утрате как психологической травме Ф. Рупперта, Д. Калшеда, Л.В. Трубицыной, Н.В. Тарабриной, Дж. Боулби, С. Рубина.

Выборку исследования составили женщины и мужчины в возрасте 19-40 лет $(\mathrm{M}=36)$.

В исследовании использовалась авторская анкета, направленная на изучение отношения общества к перинатальным утратам. Представлены результаты эмпирического исследования отношения к перинатальным потерям, видам оказания психологической помощи.

Перспектива дальнейшего исследования направлена на изучение стратегий преодоления перинатальных утрат, выбираемых женщинами, пережившими такую потерю, и созданию программы по оказанию психологического сопровождения после потери.

Ключевые слова: перинатальная утрата, горе, невынашивание беременности, выкидыш, психологическая травма. о статистике каждая 5-ая российская семья сталкивается с репродуктивными или перинатальными потерями, следовательно, для них важна квалифицированная помощь в последующей реабилитации. Статистический мониторинг перинатальных потерь в Российской Федерации за 2018 г. (коэффициент перинатальных потерь 7,23 на 1000 населения) показывает тенденцию к снижению показателей перинатальных потерь по сравнению с 2010 г. (коэффициент 10,17 на 1000 населения), тем не менее этот уровень остается высоким [4, с.26], по сравнению с развитыми странами: Великобритания - 2010 г. коэффициент 3,0 на 1000 населения, 2017 г. коэффициент 2,6 на 1000 населения; США - 2010 г. коэффициент 4,0 на 1000 населения, 2017 г. коэффициент 3,6 на 1000 населения; Япония - 2010 г. коэффициент 1,1 на 1000 населения, 2017 г. коэффициент 0,9 на 1000 населения [5]. Перинатальная (околородовая) смертность - собирательное понятие, объединяющее смерт- 
ность жизнеспособных плодов начиная с 28-й недели (с 2012 г. - с 22 недели) беременности и до начала родовой деятельности у матери, а также во время родов и смертность детей в течение первых 168 часов (7 суток) жизни $[4$, c.73].

Понятие «перинатальная потеря» включает в себя: ситуации невынашивания беременности, аборта, внематочной беременности, антенатальной и интранатальной гибели плода, неудачу при экстракорпоральном оплодотворении, гибель одного из плодов при многоплодной беременности, смерти новорожденного ребенка, в некоторых странах и смерть усыновленного младенца, а также некурабельное бесплодие $[1 ; 6]$.

Перинатальная утрата относится к психологической травме, так как это событие имеет сильное воздействие на психику женщины, разрушая привычный жизненный уклад, вторгаясь во внутренний мир потерявшего, и уничтожающее устоявшиеся связи в системе мировозрения [10; 22].

Потеря ребенка в результате мертворождения, выкидыша или неонатальной смерти признается травматическим событием в жизни. Предикторы развития осложненного горя при перинатальной утрате включают в себя: отсутствие социальной поддержки, ранее существовавшие трудности в партнерских отношениях, отсутствие выживших детей, а также двойственное отношение к такой утрате в обществе. Установлено, что риск осложненного горя особенно высок после прерывания беременности из-за аномалий развития плода [12;14; 21 ; 23].

Исследования Л.А. Пергаменщика и Е.А. Петражицкой изучавшим перинатальную потерю, как кризисное событие в жизни женщины, проводившиеся за период 20152018 гг. показали, что травмирующее действие перинатальной утраты, связано со спецификой самой потери и приводит к многочисленным психологическим и социальным последствиям. Работа с травмой перинатальной потери требует своевременной психологической помощи [8].

Завгородняя И.В. отмечает, что в ситуациях, связанных с самопроизвольным прерыванием беременности (выкидышем), для женщины проявляются все характеристики психотравмирующей ситуации, что становится психологической травмой для женщины. Отсутствие должного внимания со стороны специалистов и близких людей, при данной утрате, приводит к осложненным переживаниям работы горя и ухудшению психологического состояния обоих партнеров [7].

De Montigny F. с соавторами проведя перекрестное исследование симптомов депрессивного и перинатального горя у женщин после выкидыша, установили, что симптомы депрессии и перинатального горя сохраняются в течение длительного времени после выкидыша; особенно у бездетных женщин и / или у женщин не получивших своевременную поддержку от специалистов в медицинском учреждении [15]. Шведские исследователи поддерживают эту точку зрения обращая внимание на то, что на усиление эмоционального переживания от перинатальной утраты оказывает влияние: предыдущие неудавшиеся беременности; а также общественная изоляция и отсутствие поддержки близких [24]. Потеря ребенка в результате мертворождения, выкидыша или неонатальной смерти признается травматическим событием в жизни. Предикторы развития осложненного горя после дородовой утраты включают отсутствие социальной поддержки, ранее существовавшие трудности в отношениях или отсутствие выживших детей, а также двойственное отношение или повышенное восприятие реальности беременности. Было установлено, что риск осложненного горя особенно высок после прерывания беременности из-за аномалий развития плода [18; 20].

Султанова И.В также обращает внимание, что перинатальная утрата является психотравмирующей ситуацией не только для женщины, но и для ее партнера и близких родственников. Специфика потери может привести к саморазрушаюшему поведению и изменить существующие отношения между партнерами. Индивидуальные особенности переживания процесса горевания требуют серьезного психотерапевтического вмешательства [11].

Ситуация перинатальной утраты, подчеркивает необходимость внимательного отношения к состоянию женщины, как со стороны специалистов, так и стороны значимых для нее близких людей в целях предупреждения возникновения психологической травмы. В следствии активной психической работы при беременности, образ ребенка становится более оформленным, создается образ нового «Я» и сталкиваясь с ситуацией перинатальной потери, женщина может испытывать страхи по отношению к будущей беременности, восприятия себя как женщины способной стать матерью. При перинатальной потере происходит утрата физическая (гибель эмбриона, плода, ребенка) и символическая (статуса родительства, представлений, мечты, потери «Я» или его части и т.д.). Такая форма двусмысленности, связанная с перинатальной потерей, способна привести к тому, что женщина может оказаться в своеобразной социальной изоляции. Так как с одной стороны информация о беременности не всегда разглашается, особенно на ранних сроках беременности; а с другой - общество не всегда может оценить значимость потери для женщины, и даже партнер или близкое окружение, избегают разговоров о потере или словами поддержки обесценивают ее. Отсутствие социальной поддержки, внимания и признания факта значимости потери для женщины со стороны медицинского персонала, также способствует формированию социальной изоляции, и реакциям осложненного 
горя $[3 ; 9 ; 13 ; 16 ; 17 ; 19]$.

\section{Материалы и методы исследования}

Цель исследования: выявить различия в отношении мужчин и женщин к перинатальным утратам, их представлений о перинатальной утрате, а также видам помощи при перинатальных утратах.

В исследование приняли участие 84 человека, В возрасте от 19 до 61 года, из них 57 \% женщин (M=34) $19 \%$ мужчин (M = 39). Из них: жители города СанктПетербурга - 55\%; жители Ленинградской области - 12\%; жители других регионов России - 20\%; проживающие в других странах - 13\%. 67\% опрошенных имеют высшее образование, 23\% - два и более высших образования; 2\% -ученую степень; 4\%- неоконченное высшее образование; 2\% - среднее профессиональное образование; по $1 \%$ опрошенных имеет неполное среднее и среднее образование соответственно. 52\% опрошенных состоят в браке; $19 \%$ - разведены; $16 \%$ - не состоят в браке; 13 \% - состоят в партнерских отношениях (незарегистрированном браке). Имеющие детей - $62 \%$, не имеющие детей - 33\%, планирующие 5\%. Опыт перинатальной потери имели $23 \%$ опрошенных.

Были использованы методы: опрос - авторская анкета, статистические методы (descriptive statistics, Mann Whitney U test, Pearson's chi-squared test, Wilcoxon Matched Pairs Test).

Достоверность результатов обеспечивалась анонимностью анкетирования и достаточной мотивацией респондентов. Перед исследованием с респондентами проводилась беседа по объяснению целей и процедуры исследования.

Анкета была составлена согласно методологии и методов социологического исследования [12]. Анкета состояла из 17 вопросов, разделенных на следующие блоки.

Первый блок- состоит из 5 прямых полузакрытых вопросов, содержание которых раскрывает: ситуации, относящиеся к перинатальным потерям; отношение к перинатальной потере, тип совладающего поведения.

Второй блок содержит вопросы, направленные на прояснение эмоционального поведения и его интенсивности, при перинатальной потере. Для устранения эффекта психологической ригидности, в блоке предусмотрены «вопросы-глушители».

Третий блок - состоит из полузакрытых вопросов, проясняет отношение к видам помощи для женщин, пережившим перинатальную утрату; необходимость информирования семьи, близкого и социального окру- жения о перинатальной потере; отношение общества к женщинам, перенесшим перинатальную потерю.

Четвертый блок - социально-демографические характеристики; вопросы открытого типа. Один вопрос «личный опыт переживания перинатальной утраты» имеет закрытую форму ответа: «Да» или «Нет».

Вопросы содержательного блока анкеты составлены из позиций с 1 по 10.

\section{Результаты исследования и их обсужление}

В результате анализа полученных данных можно говорить о том, что что основным видом перинатальной потери и женщины и мужчины считают смерть новорожденного после родов (91\%). Далее, в порядке убывания следует: мертворождение (86\%); самопроизвольный выкидыш на поздних сроках (80\%); гибель одного из плодов при многоплодной беременности (74\%); самопроизвольный аборт на ранних сроках и аборт по медицинским показаниям по 67\% соответственно; аборт по желанию женщины (35\%); 4 \% опрошенных отнесли к другим видам перинатальных потерей: «неудачные попытки ЭКО, гибель плода ребенка у суррогатной матери (у женщины-донора)»; «аборт по желанию, тоже можно отнести, но это индивидуально».

Подавляющее большинство опрошенных считают перинатальную потерю травмирующим событием, причиняющее вред психическому здоровью женщины (48\%). Полученные результаты согласуются с результатами других исследований, отмечающих наличие у женщин, переживших перинатальную потерю: высокую склонность к депрессиям; отстутствие жизнененной активности, растройства пищевого поведения, инсомнию, чувство тоски и отчаяния [7;8;9;1 1;15; 16;19;20; 22]. 20\% считают, что перинатальная потеря - это событие, которое вызывающее у женщины различные эмоциональные реакции, в том числе, имеющие противоречивый характер. Стрессом для женщины, но не такой, как смерть близкого взрослого или ребенка, считают (11\%). Потерей человека, по отношению к которому женщина чувствует сильную эмоциональную привязанность (17\%). Только 5\% считают перинатальную потерю процессом трансформации связи женщины с «ушедшим» ребенком.

Основной стратегией, чтобы справиться с утратой новорожденного или ребенка во время беременности является: принять реальность потери, испытать боль горя, приспособиться к среде, в которой нет умершего и эмоционально отдалиться от него (62\%). Найти смысл, чтобы жить дальше (23\%). Укреплять свое здоровье и запланировать новую беременность (11\%).

Усыновить ребенка (4\%). Продолжать жить так же, как и раньше (1\%). 
Причины, вызывающие потерю женщиной ребенка во время беременности или после родов распределились следующим образом: болезни или травмы во время беременности (89\%); хронические заболевания женщины (71\%); случайные факторы, не связанные с условиями жизни и здоровьем (51\%); аборты в прошлом (48\%); неправильное поведение, вредные привычки женщины (48\%); наследственные факторы (44\%); старший возраст женщины (38\%); неблагоприятные условия жизни (36\%); семейные конфликты (29\%); другое (2\%).

Всем участникам пороса было предложено определить, является ли потеря женщиной ребенка во время беременности или после родов, ситуацией касающейся только женщины, или ситуацией, затрагивающей мужчину (партнера), или всю семью. 50 \% отнесли перинатальную потерю к ситуации касающейся всей семьи, родственников женщины. Переживание, которое касается только женщины (25\%). Ситуация, которую переживает и мужчина (25\%). Это соотносится с другими исследованиями посвященные мужскому горю после перинатальной потери показывают, что переживание горя у мужчин очень разнообразны. По сравнению с женщинами мужчины могут сталкиваться с другими проблемами, включая ожидания поддержки партнеров-женщин и отсутствие общественного признания их горя и последующих потребностей [9;19;20;23;24]. Важным моментом является тот факт, что больше половины опрошенных респондентов (56\% - женщин, 57\% - мужчин) считают, что женщина сама должна принимать решение о том, делится ли ей информацией о перинатальной потере или нет. Причем мужчины (31\%) более категоричны, в ответе на вопрос «нет, это слишком личное»; хотя практика психологического консультирования при работе с утратой, показывает, что какими бы болезненными ни были чувства, состояние человека, переживающего утрату, восстанавливается быстрее, если горюющий позволит себе переживать горе в полной мере [7]. Женщины, больше придерживаются этой позиции (19\%), проговаривание ситуации поможет справиться с горем; мужчины полностью не разделяют это мнение. Среди респондентов есть группа людей, которые не имеют сложившегося мнения относительно того, является ли необходимостью для женщины делится информацией о перинатальной потеpe (11\% - мужчины и 7\% женщины). Также 5\% опрошенных выбрали свой вариант ответа, среди которых: «в зависимости от состояния женщины»; «у каждого человека это индивидуально»; «только тому, кому женщина доверяет».

Следующий немало важный вопрос нашего исследования, каким образом женщины и мужчины видят необходимость помощи женщине при перинатальной потере: профессиональную помощь специалистов, помощь партнера, близкого окружения и социального окружения. Женщины и мужчины поставили на первое место обращение за профессиональной психологиче- ской помощью (82\%). 75\% считают, что важна поддержка и помощь партнера; 58\% отметили поддержку семьи, родственников; 30 \% помощь друзей. Информационная поддержка от врачей 58\%; при этом оказание медицинской (специализированной) помощи (36\%). Обращение к религии, духовным практикам (20\%). 5\% опрошенных считают, что помощь не нужна, женщина может справиться сама. Только 1\% считают, что при перинатальной потере женщине необходимы все виды помощи.

Как мы указывали ранее, одной из причин приводящей к осложненному горю, может являться фактор социальной изоляции, в которой может оказаться женщина, пережившая перинатальную утрату. Женщина, не всегда готова делится информацией о перинатальной потере, особенно если это произошло на ранних стадиях беременности. Более того, не всегда другие люди способны оценить значимость такой потери для женщины; «слова поддержки» с их стороны могут быть неприятны для родителей; поэтому даже близкие могут избегать общения после перинатальной потери и предпочитают не затрагивать эту тему.

Соответственно, нам было важно получить ответ на вопрос: как относится большинство людей к женщине, потерявшей ребенка (плод) во время беременности или после родов. Результаты достаточно противоречиво показывают отношение общества к этому вопросу. Так $25 \%$ опрошенных считают, что общество относится к перинатальной потере как к горю (утрате). При этом 24\% опрошенных, считают, что «ничего особенно страшного не произошло». 18\% проявляют сочувствие и желание помочь; 17 \% считает, что общество равнодушно относится к такой потере. 8\% полагает, что женщина сама виновата в утрате ребенка. 5 \% полагает, что после потери ребенка пострадает психическое здоровье женщины. 4 \% считают, что все зависит от обстоятельств.

Нами было выдвинуты предположения: 1) Мужчины и женщины могут иметь различное отношение к видам перинатальной потере и видам необходимой помощи женщинам. 2) Существуют различия между женщинами имеющих детей и женщинами не имеющих детей, в отношении перинатальных утрат. 3) Женщины, имеющие опыт перинатальной потери

Для проверки гипотез были использованы статистические методы (descriptive statistics, Mann Whitney U test, Pearson's chi-squared test, Wilcoxon Matched Pairs Test).

Проведенный анализ показал, что и мужчины и женщины рассматривают перинатальную потерю, как значимое событие в жизни, независимо от гестационного или неонатального возраста ребенка. При этом вид перинатальной потери «гибель одного из плода при многоплодной беременности» обнаруживает тенденцию к различию на уровне 5\% между не состоящими в браке 
(мужчины - 37,5\%; женщины - 18,8\%) и состоящими в браке (мужчины - 62,5\%; женщины - 81,2\%).

Женщины, состоящие в браке $(63,64 \%)$, считают перинатальную потерю травмирующим событием, способным причинить вред психическому здоровью женщины. С этим утверждением согласны (36,36\%) мужчин, имеющих семейное положение. При этом не состоящие в браке (70\%) мужчин и (30\%) женщин, не считают перинатальную потерю травмирующим событием.

Существенное различие между мужчинами и женщинами обнаружено в мнении о необходимости обращения за психологической помощью, так 38,10\% мужчин и $11,1 \%$ женщин считают, что такая помощь не нужна; при этом 61,9\% мужчин и 88,99\% женщин считают такую помощь необходимой.

Существует тенденция к проявлению различий между мнением мужчин и женщин, что женщине, пережившей перинатальную потерю «помощь не нужна совсем, может справиться сама» (различия на уровне $5 \%$ значимости). Большая часть женщин $(98,4 \%)$ и мужчин $(85,7 \%)$ считают, что помощь необходима; но при этом большее количество мужчин (14,3 \%) считает, что женщина «справиться сама».

Мужчинам свойственно считать, что общество не относится к женщине, переживающей перинатальную потерю, как к переживающей горе, утрату (90,48\%), (69,84\%) женщин разделяют это мнение. При этом $(30,16 \%)$ женщин и $(9,52 \%)$ мужчин, наоборот считает, что общество относит перинатальные потери к горю и утрате.

Таблица 1.

Отношение мужчин и женщин к перинатальной потере

\begin{tabular}{|l|c|c|}
\hline \multicolumn{3}{|c|}{ Мужращение за помощью к психологу } \\
\hline Считают важным & $61,9 \%$ & $88,99 \%$ \\
\hline Не считают важным & $38,1 \%$ & $11,1 \%$ \\
\hline \multicolumn{3}{|c|}{ Х2=6,965980; df=1; $p=0,00831$} \\
\hline \multicolumn{3}{|c|}{ помощь не нужна, справиться сама } \\
\hline Считают важным & $85,7 \%$ & $98,4 \%$ \\
\hline Не считают важным & $14,3 \%$ \\
\hline \multicolumn{3}{|c|}{ Х2=5,6; df=1; $p=0,01796$} \\
\hline \multicolumn{1}{|c|}{ Отношение общества к перинатальной потере, как к горю, утрате } \\
\hline Согласны & $9,52 \%$ & $30,16 \%$ \\
\hline Не согласны & $90,48 \%$ & $69,84 \%$ \\
\hline \multicolumn{3}{|c|}{ X2=3,57672; df=1; $p=, 05460$} \\
\hline
\end{tabular}

Были обнаружены существенные различия между имеющими опыт перинатальных потерей и не имеющи- ми такого опыта, в том, что относится к видам перинатальных потерь. Так $(91,67 \%)$ имеющие опыт перинатальных утрат относят «аборт по медицинским показаниям» и «гибель одного из плода при многоплодной беременности» к перинатальным потерям. Основным видом помощи при переживании перинатальной потери имеющие опыт перинатальных потерь и не имеющие опыт перинатальных потерь, считают помощь семьи, родственников. Только 4,17\% имеющих опыт перинатальных потерь считают, что обращение к религии и духовным практикам, способно помочь справиться с утратой. Вероятно, это связано с тем, что женщины в ситуации перинатальной потери чувствует себя опустошенной, жизнь воспринимается ими как пустая и лишенная смысла. Очевидно, что этот вопрос требует дальнейшего изучения возможных различий в эмоциональном состоянии женщин, и особенностях отношения к перинатальным утратам произошедших на различных гестационных сроках перинатальной потери.

Таблица 2.

Отношение к пренатальной потере, при опыте перинатальной утраты и без нее

\begin{tabular}{|c|c|c|}
\hline & Имеющие опыт ПУ & Не имеющие опыт Пу \\
\hline \multicolumn{3}{|c|}{ Аборт по медицинским показаниям } \\
\hline Относят к ПУ & $91,67 \%$ & $56,67 \%$ \\
\hline Не относят к ПУ & $8,33 \%$ & $43,33 \%$ \\
\hline \multicolumn{3}{|c|}{$X 2=11,05844 ; d f=1 ; p=0,00088$} \\
\hline \multicolumn{3}{|c|}{ Гибель одного из плода при многоплодной беременности } \\
\hline Относят к ПУ & $91,67 \%$ & $65,00 \%$ \\
\hline Не относят к ПУ & $8,33 \%$ & $35,00 \%$ \\
\hline \multicolumn{3}{|c|}{$X 2=7,156153 ; d f=1 ; p=0,00747$} \\
\hline \multicolumn{3}{|c|}{ Обращение к религии, духовным практикам как помощь при Пу } \\
\hline Согласны & $4,17 \%$ & $26,67 \%$ \\
\hline Не согласны & $95,83 \%$ & $73,33 \%$ \\
\hline \multicolumn{3}{|c|}{$X 2=6,715487 ; d f=1 ; p=0,00956$} \\
\hline
\end{tabular}

Таким образом, можно говорить о том, что подавляющее большинство относит к перинатальной потере - смерть новорожденного после рождения. Соответственно, другие виды перинатальных утрат, такие: мертворождение; гибель одного из плода при многоплодной беременности; самопроизвольные аборты на ранних и поздних сроках беременности; аборты по медицинским показаниям; а также потеря беременности при ЭКО могут не признаваться, травмирующими событиями, оказывающими влияние на женщину, пережившую перинатальную потерю.

Участники опроса считают, что в обществе не признается тот факт, что эмоциональная связь с ребенком начинается у матери с началом беременности, скорее при- 
нято считать, что эти отношения возникают с момента рождения и наличия новорожденного ребенка в семье.

Амбивалентное отношение общества к перинатальным потерям нивелирует родительское горе, и может лишать женщину прав на естественное выражение своего горя и страданий. Возникающий при этом феномен бесправного горя, может привести к осложненному горю.

Для нормального протекания горя при перинатальной утрате женщине необходима профессиональная психологическая, информационная и медицинская помощь; при этом поддержка партнера и семьи также имеет важное значение.

Заслуживает внимание, тот факт, что женщина сама должна принимать решение о необходимости, делится информацией о перинатальной утрате с родными и близкими. Такое мнение, должно уважаться близким социальным окружением и обществом.

\section{ЗакАючение}

Перинатальная потеря является тяжелой утратой, оказывающей влияние как на женщину, так и на других членов семьи. Перинатальная потеря часто включает в себя ощущение биологической неудачи, утрату идентичности, ощущение отсутствия общих воспоминаний и снижение надежд на будущее.

Поскольку смерть ребенка кажется такой неестественной, внезапной и лишенной смысла, женщине необходима эмоциональная поддержка от близких и специалистов, оказывающих помощь. Семья и близкие должны понимать, как важно быть с родителями и позволять родителям, особенно матерям, говорить о потере. Медицинским работникам следует избегать любых заявлений, которые сводят к минимуму чувства женщины или вызывают чувство вины.

Результаты настоящего исследования дают начальное понимание в отношении общества к перинатальным потерям, и потребностям женщины в социальной поддержке после перинатальной потери. Дальнейшие исследования, необходимо направить на вопросы: связанные с психологической поддержкой перинатальной потери, и формированию программ по оказанию психологической помощи как женщинам, так и семье в целом.

ЛИТЕРАТУРА

1. Большая Медицинская Энциклопедия (БМЭ), под редакцией Петровского Б.В., 3-е издание Категория: Том 19 [электронный ресурс htpp//бмэ.opг/index. php/ Перинатальная смертность] дата обращения 24.08.2020

2. Глушенкова В.А., Цыбульская И.С., Суханова Л.П. Проблемы перинатальной смертности в России // Менеджер здравоохранения. 2007. №9.

URL: https://cyberleninka.ru/article/n/problemy-perinatalnoy-smertnosti-v-rossii (дата обращения: 21.10.2020).

3. Гнездилов А.В. Психология и психотерапия потерь. Пособие по паллиативной медицине для врачей, психологов и всех интересующихся проблемой. СПб.: Речь, 2002. 162 c.

4. Демографический ежегодник России. 2019: Стат.сб.//Росстат. М., 2019. 252 с.

5. Демоскоп Weekly № 865 - 8661 - 30 августа 2020 Институт демографии Национального исследовательского университета «Высшая школа экономики» URL: http://www.demoscope.ru/weekly/app/app40neo.php (дата обращения: 18.08.2020)

6. Добряков И.В., Блох М.Е., Фаерберг Л.М. Перинатальные утраты: психологические аспекты, специфика горевания, формы психологической помощи // Журнал акушерства и женских болезней. - 2015.T. 64. №3. С. 4-10. URL: doi: 10.17816/JOWD6434-10 (дата обращения: 24.09.2020).

7. Завгородняя И.В. Невынашивание беременности как переживание перинатальной утраты // Клиническая и медицинская психология: исследования, обучение, практика: электрон. науч. журн. - 2017. - T. 5, № 2(16) URL: http://medpsy.ru/climp (дата обращения: 20.09.2020).

8. Пергаменщик Л.А, Петражицкая Е.А. Перинатальная потеря. Как кризисное событие в жизни женщины. Журнал Белорусского государственного университета. Философия. Психология. 2020. С. 77-84

9. Полуэктова 0.Г. Травма потери ребенка. Вестник новых медицинских технологий. Электронное издание - 2013 - N 1, С.151-154.

10. Психология кризисных и экстремальных ситуаций: учебник/под ред. Н.С. Хрусталевой - СПб.: Изд-во С.-Петерб. ун-та, 2018.748 с, с. 385-388.

11. Султанова И.В. Психологические аспекты перинатальных утрат. Вестник современных исследований. 2019. № 3.11 (30). С. 168-173.

12. Ядов В.А. Социологическое исследование: методология, программа, методы - М.: Наука, $1972-266$ с.

13. Badenhorst, W., \& Hughes, P. (2007). Psychological aspects of perinatal loss. Best practice \& research. Clinical obstetrics \& gynaecology, 21(2), $249-259$. https://doi.org/10.1016/j.bpobgyn.2006.11.004

14. Boss, P. (2004). Ambiguous loss research, theory, and practice: Reflections after 9/11. Journal of Marriage and Family, 66(3), p. 551-566. URL: https://doi. org/10.1111/j.0022-2445.2004.00037.x (дата обращения: 23.08.2020).

15. Corno, G., Bouchard, S., Baños, R. M., Rivard, M. C., Verdon, C., \& de Montigny, F. (2020). Providing Psychological and Emotional Support After Perinatal Loss: Protocol for a Virtual Reality-Based Intervention. Frontiers in psychology, 11, 1262. URL: https://doi.org/10.3389/fpsyg.2020.01262 (дата 0бращения 24.08.2020)

16. deMontigny, F., Verdon, C., Meunier, S., \& Dubeau, D. (2017). Women's persistent depressive and perinatal grief symptoms following a miscarriage: the role of childlessness and satisfaction with healthcare services. Archives of women's mental health, 20(5), 655-662. URL: https://doi.org/10.1007/s00737-017-0742-9 
17. Doka, K.J. Disenfranchised grief. //K.J. Doka (Ed.), Disenfranchised grief: Recognizing hidden sorrow. Lexington, MA: Lexington Books, 1989. p.3-11. (дата 06ращения: 20.08.2020).

18. Doka K.J., Aber R. Psychosocial loss and grief // Disenfranchised grief: Recognizing hidden sorrow / ed. by K.J. Doka. Lexington, MA: Lexington Press, 1989. P. 187 - 197.

19. Lang A., Fleiszer A., Duhamel F. (2011) Perinatal Loss and Parental Grief: The Challenge of Ambiguity and Disenfranchised Grief, OMEGA-Journal of Death and Dying - October 2011 OMEGA, Vol. 63(2) 183-196, 2011

20. Leon I.G. (2008). Helping families cope with perinatal loss. The Global Library of Women's Medicine, Retrieved online April 1, 2010: URL: http://www.glowm.com/ index.html?p=glowm.cml/section_view\&articleid=417 (дата обращения 29.08.2020)

21. Kersting, A., \& Wagner, B. (2012). Complicated grief after perinatal loss. Dialogues in clinical neuroscience, 14(2), 187-194.

22. Meredith, P., Wilson, T., Branjerdporn, G., Strong, J., \& Desha, L. (2017). «Not just a normal mum»: a qualitative investigation of a support service for women who are pregnant subsequent to perinatal loss. BMC pregnancy and childbirth, 17(1), 6.URL: https://doi.org/10.1186/s12884-016-1200-9 (дата обращения 01.09.2020)

23. Rando, T.A. (1986). The unique issues and impact of the death of a child. In T. A. Rando (Ed.), Parental loss of a child (pp. 5-43). Champaign, IL: Research Press Company.

24. Scheidt C.E., Waller N., Wangler J. Perinatalverlust-Prävalenz, klinisches Bild und Behandlung-eine Ubersicht über den aktuellen Forschungsstand [Mourning after perinatal death-prevalence symptoms and treatment-a review of the literature]. Psychotherapie, Psychosomatik, medizinische Psychologie, 57(1), 4-11. URL: https://doi.org/10.1055/s-2006-951906

25. Volgsten $H$, Jansson C. Svanberg A. Longitudinal study of emotional experiences, grief and depressive symptoms in women and men after miscarriage Midwifery Volume 64, September 2018, Pages 23-28September 2018, Pages 23-28 https://doi.org/10.1016/j.midw.2018.05.003 (дата 0бращения 21.09.2020)

() Маркман Елена Валерьевна (lev195197@gmail.com).

Журнал «Современная наука: актуальные проблемы теории и практики»

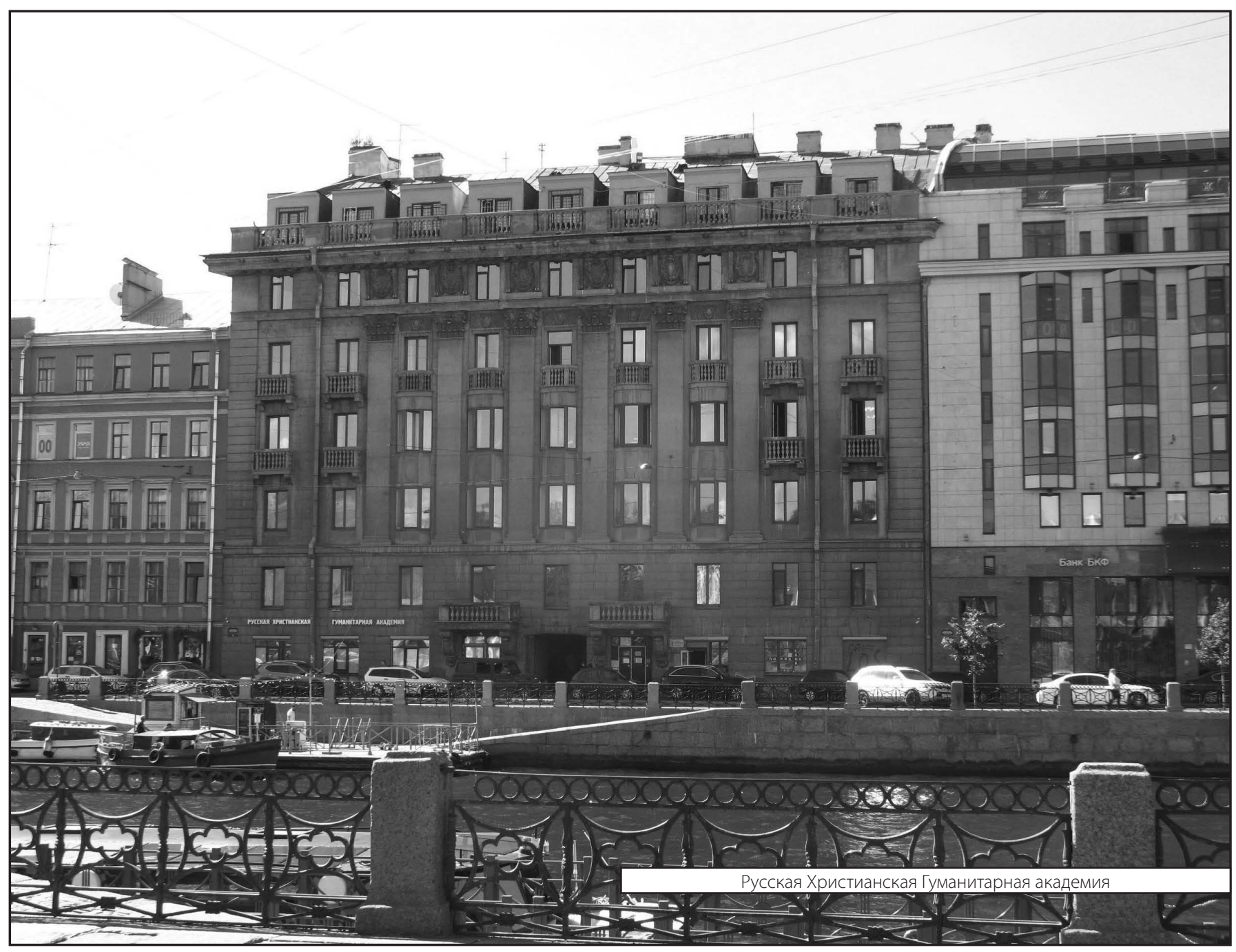

